\title{
The Effect of Rhodium (III) Sulfate and Clove Oil Catalysts on The Droplet Combustion Characteristics of Castor Oil
}

\author{
Purnami $^{1 *}$, I.N.G Wardana ${ }^{1}$, Nurkholis Hamidi ${ }^{1}$, Mega Nur Sasongko, ${ }^{1}$ Djarot B \\ Darmadi ${ }^{1}$.
}

${ }^{1}$ Mechanical Engineering Brawijya University

J1 MT Haryono 167, Malang, 65145, INDONESIA

*Corresponding Author

DOI: https://doi.org/10.30880/ijie.2019.11.05.009

Received 8 January 2019; Accepted 17 April 2019; Available online 10 August 2019

\begin{abstract}
The petroleum fuels reserves from fossils are getting smaller, even though petroleum consumption is increasing. Given the increasingly limited amount of fuel derived from fossils, it is necessary to do research to look for alternative fuels. Castor oil is one of the alternative plant oils that can replace petroleum fuels. Castor oil is a non-food crop which numbers is relatively many in Indonesia. But Castor oil has limitations on its combustion property, so combustion of Castor oil cannot produce energy that is as large as petroleum combustion. It is necessary to add catalysts to improve the combustion properties of Castor oil. In this study, the addition of Rhodium (III) Sulphate and Clove oil was performed to improve the Castor oil combustion properties. Addition of catalyst is intended to reduce dissociation energy requirements, so that the combustion reaction is faster. The addition of Rhodium (III) sulfate and Clove oil catalysts is $100 \mathrm{ppm}, 200 \mathrm{ppm}, 300 \mathrm{ppm}$ and $400 \mathrm{ppm}$. The results showed that the addition of catalysts affected the Castor oil combustion characteristics. The more addition of Rhodium (III) Sulfate catalysts and Clove oil can increase the combustion temperature value, reduce the ignition delay, burning rate, and flame dimensions. Rhodium (III) Sulphate is more effective in influencing the combustion characteristics of Castor oil compared to Clove oil catalysts because it has more magnetic field sources in one atom that disrupt the bonding of Castor oil compared to Cloveoil. The addition of a mixture of clove oil and Rhodium (III) sulfate in Castor oil causes lower combustion characteristics compared to the Rhodium (III) sulfate catalyst. However, the performance of its blend catalyst on the combustion characteristic was still preferable compared to clove oil alone
\end{abstract}

\section{Introduction}

The world's dependence on fossil-based fuel needs continues to increase. While fossil-based fuels are nonrenewable energy. World petroleum reserves are becoming increasingly rare whereas their consumption is increasing. If no new energy source is found, the world will experience a serious energy crisis. Given the increasingly limited energy derived from fossils, it takes effort to look for alternative fuels instead of petroleum. The use of plant oil is one of the efforts to replace dependence on fuel oil [1]. Plant oils are available in large quantities and types in Indonesia, for example coconut oil, palm oil, candlenut, peanuts, Castor and jatropha cruces [2].

The use of plant vegetable oil so far as a substitute for fuel oil has not produced good combustion, due to the different physical and chemical properties of fossil fuels [3]. Castor oil is one of the plant oils that can be used as an alternative fuel. Castor oil is one of the potential plant oils. However Castor oil has a double bond on its alkyl chains which causes a reduction in combustion properties. Castor oil is plant oil obtained from the Ricinus communism and Jatropha [4] extraction. It is a type of shrub or tree plant that is resistant to drought and grows in the lowlands [5]. The Castor oil composition is triglyceride molecules which consist of glycerol [6] namely alcohol with 3 carbon chains as 
the main chain and 3 fatty acids branches with 18 carbon or 16 carbon chains. Fatty acid content in Castor oil (ricinus communis) as in table 1.

Table 1. Fatty acid composition of Castor seed oil

\begin{tabular}{ccc}
\hline No & Fatty Acids & $\begin{array}{c}\text { Concentration } \\
(100 \%)\end{array}$ \\
\hline 1 & Palmitic acid & $4.2 \%$ \\
2 & Stearic acid & $6.9 \%$ \\
3 & Oleic acid & $43.1 \%$ \\
4 & Linoleic acid & $34.3 \%$ \\
5 & Other acid & $1.4 \%$ \\
\hline
\end{tabular}

To increase combustion properties, then Castor oil needs a catalyst administer to stimulate electrons to leave the molecule. Molecules that lose electrons become charged and break easily. The addition of clove [7] and Rhodium (III) sulfate [8] catalysts to oil combustion has not been performed by the researchers. Clove oil is obtained through steam distillation of cloves and clove trees. Dried cloves contain eugenol 80.94\%. Whereas clove leaves contain $82.13 \%$ eugenol. The main component of clove oil is an aromatic compound called eugenol (72-90\%). The eugenol thick structure [9] is expected to reduce the Van Der Walls bond strength between molecules and carbon chains. The molecular bond composition in cluve oil can be seen in Figure 1.<smiles>CC(C)c1ccc(O)c(C=O)c1</smiles>

Figure 1. Eugenol structure of cluve oil

Rhodium used as a catalyst in this study is a form of ionic compounds from Rhodium namely Rhodium (III) Sulphate with the chemical formula $\mathrm{Rh}_{2}\left(\mathrm{SO}_{4}\right)_{3}$. Both clove oil and Rhodium (III) sulfate can produce a magnetic field produced from electron resonance which will affect the structure of Castor oil.

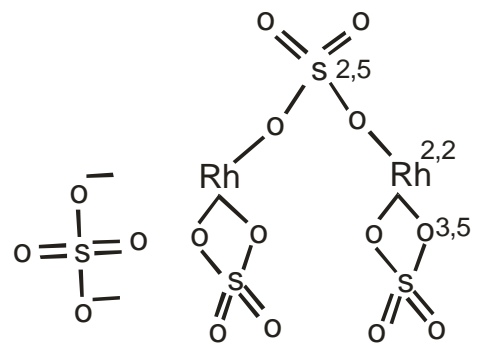

(a)

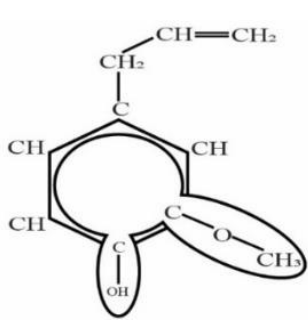

(b)

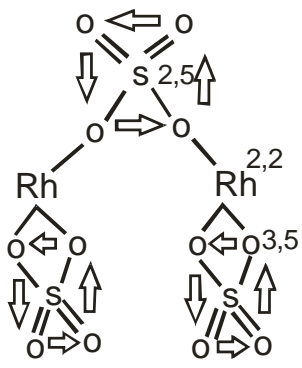

(c)

Figure 2. (a) Lewis structure of $\mathrm{SO}_{4}{ }^{2--}$ anions. (b) $\mathrm{Rh}_{2}\left(\mathrm{SO}_{4}\right)_{3}$ ion bonds. (c) Resonance illustration of clove oil and Rhodium (III) Sulphate

\section{METHOD}

In this study, Rodium (III) sulfate and clove oil catalysts were added on Castor oil droplets combustion. Addition of Rodium (III) sulfate and clove oil by 100 ppm, 200 ppm, 300 ppm and 400 ppm. This research was performed at room temperature ranging between $27^{\circ} \mathrm{C}-35^{\circ} \mathrm{C}$ and the pressure was considered constant $716 \mathrm{mmHg}$. The research tool scheme can be seen as shown in Figure 3. 


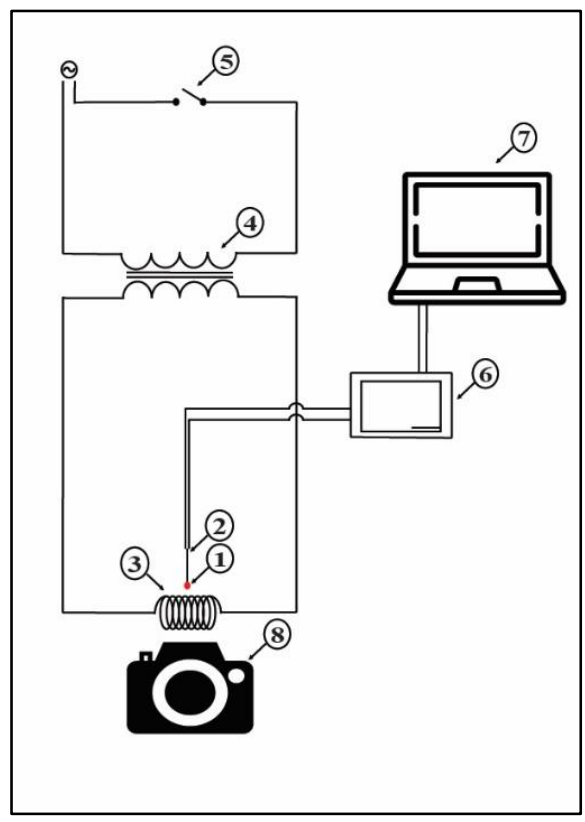

1. Droplet

2. Thermocouple

3. Heater

4. Tranformator

5. Electric switch

6. Data Logger

7. Computer

8. Camera

Figure 3 Research tool scheme

Camera was used to record the Castor oil droplet combustion process that has been added with the catalyst. The recording process was performed starting from heating up the Castor oil until the Castor oil burns out. The results obtained by the camera were then processed using Auto-Cad to obtain data in the form of combustion duration, droplet diameter changes, and flame dimensions. Thermocouple was used to measure the combustion temperature that occured. Castor oil combustion characteristics measured in this study include combustion temperature, ignition delay [10], burning rate, and flame dimensions.

\section{RESULTS AND DISCUSSIONS}

The effect of adding clove oil and rhodium (III) sulfate to the combustion temperature of Castor oil droplets can be seen in Figure 4.

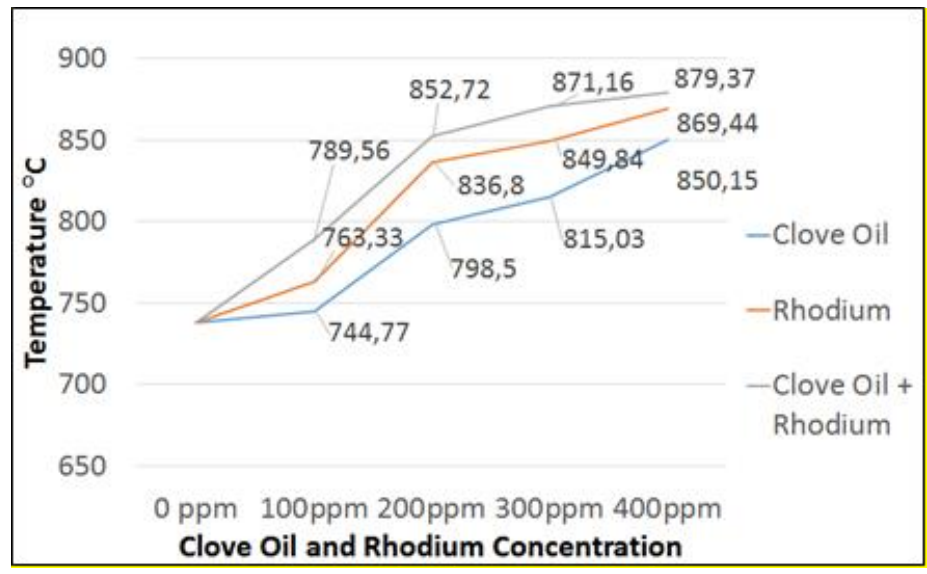

Figure 4 The Effect of addition of clove oil and Rhodium (III) Sulphate on combustion temperatures of Castor oil droplets

From the research as shown in Figure 4, the temperature value increases along with the catalysts addition, both clove oil and Rhodium (III) Sulphate. The rising combustion temperature is caused by the ability of the catalyst to accelerate the reaction, so that collisions between charged molecules and atoms random movements are getting faster. This causes a rapid oxidation process and has an impact on the increase in combustion temperature. In a mixture of Castor oil with clove oil and Rhodium (III) Sulphate has a higher temperature because the visualization of the flame is seen soot, as shown in Figure 5. Soot is formed due to atomic agglomeration. In general, aromatic hydrocarbons have the highest tendency to form soot. Clove oil is included in aromatic compounds. 


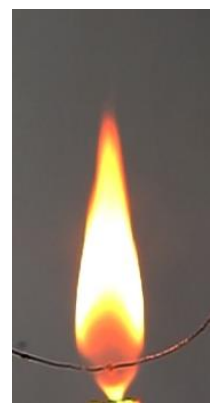

Figure 5. Soot on Castor oil mixture with clove oil and Rhodium (III) Sulphate

The effect of adding clove oil and rhodium (III) sulfate to the ignition delay of Castor oil droplets combustion can be seen in Figure 6.

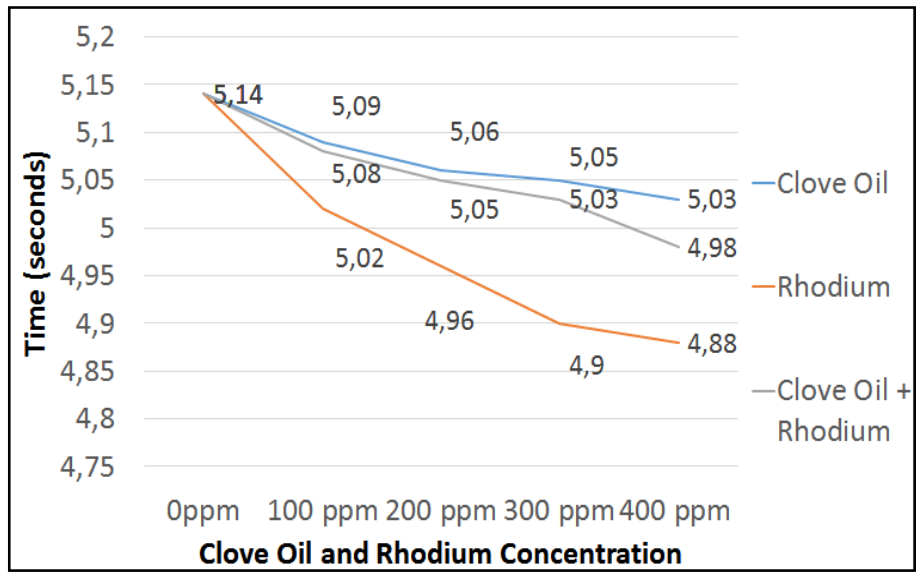

Figure 6. Addition of clove oil and Rhodium (III) Sulphate to the ignition delay for burning Castor oil droplets

From the research, it was found that the addition of $400 \mathrm{ppm}$ had the lowest ignition delay value. The ignition delay value of clove oil and Rhodium (III) Sulphate addition both tend to decrease as the catalyst increases. This happens because clove oil and Rhodium (III) Sulphate accelerates the combustion reaction because it creates electromagnetic forces that interfere electrons in the Castor and oxygen so that the activation energy needed to react fuel and oxygen is reduced. The ignition delay value produced by Rhodium (III) Sulphate shows that Rhodium (III) Sulphate is more effective in influencing ignition delay. This happens because Rhodium (III) sulfate has more influence which decreases the combustion activation energy which causes the combustion to occur relatively faster. This is because Rhodium (III) Sulphate has more magnetic fields in one atom compared to clove oil.

The effect of adding clove oil and rhodium (iii) sulfate to the combustion burning rate of Castor oil droplets can be seen in the following figure 7 .

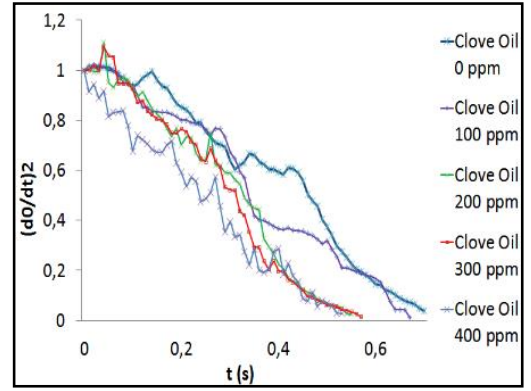

(a)

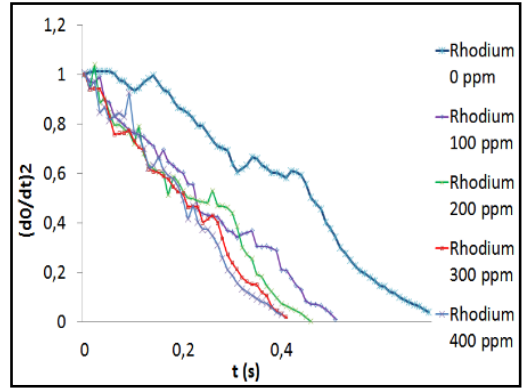

(b)

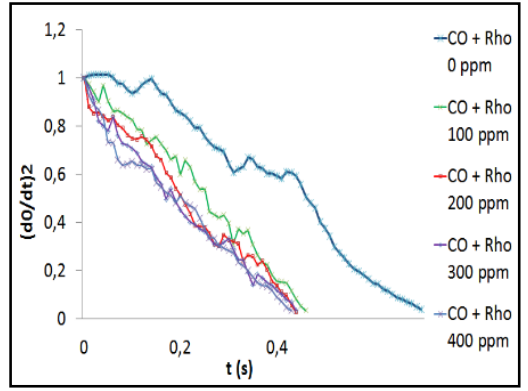

(c)

Figure 7. Evolution of droplet combustion for three different catalyst (a) clove oil, (b) Rhodium (III) Sulphate, (c) Clove oil and Rhodium (III) Sulphate

From the burning rate data in Figure 7, it can be seen that along with the addition of clove oil and Rhodium (III) sulfate, the burning rate is faster. Addition of clove oil and Rhodium (III) Sulphate can reduce the activation energy needed to react oxygen with Castor oil, so that combustion occurs faster. The burning rate produced by Rhodium (III) Sulphate shows that it is more effective in affecting the burning rate. Rhodium (III) Sulphate has more effect because it 
has more magnetic fields in one atom that disrupt the bonding of Castor oil compared to clove oil. Structure of clove oil also affect the burning rate. Glycerol will burn at the end of combustion because it has a higher flame point than other structure.

The addition effect of clove oil and rhodium (III) sulfate to the visualization of the Castor oil droplet combustion flame seen in figure 8.

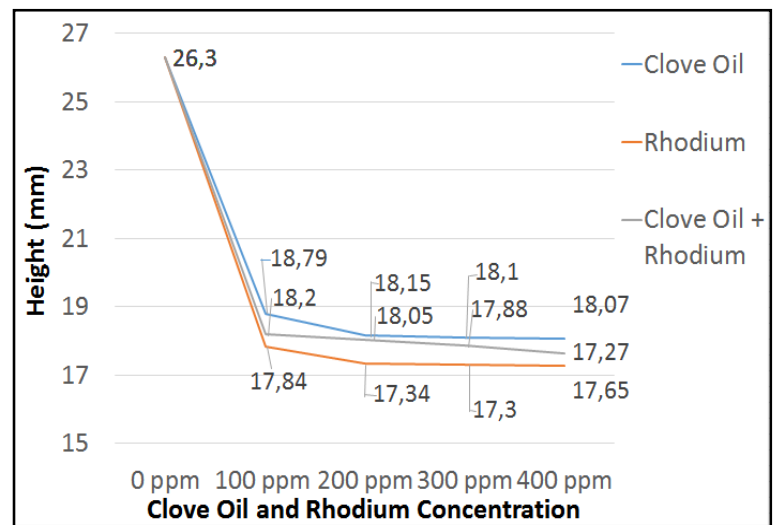

(a)

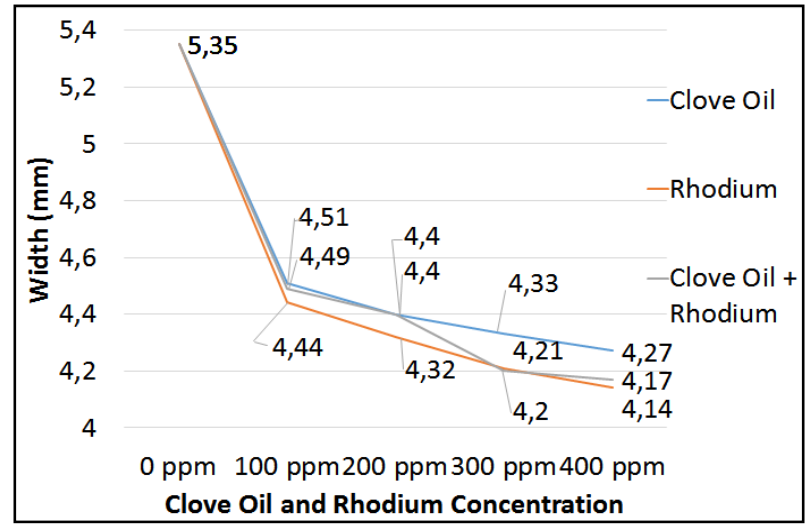

(b)

Figure 8 The visualization of the Castor oil droplet combustion flame with clove oil and Rhodium (III) Sulphate catalyst (a) flame height, (b) width of Castor oil droplet flame

In figure 8a. shows the variations effect in the addition of clove oil and Rhodium (III) Sulphate to the flame height of Castor oil droplets combustion. From the data above, clove oil has a longer flame length compared to Castor oil mixture with Rhodium (III) Sulphate. Pure Castor oil has the greatest length. In figure 8b. shows the variations effect in the addition of clove oil and Rhodium (III) Sulphate to the flame width of the Castor oil droplet combustion. From the data above Rhodium (III) Sulphate has a shorter flame width compared to a mixture of Castor oil and clove oil. Pure Castor oil has the largest flame width.

It can be observed that the combustion process quickly causes the produced flame length to be smaller. This is because the flame length is inversely proportional to molecular diffusion. The higher the percentage of clove oil and Rhodium (III) sulfate added to Castor oil, the higher the rate of combustion reaction. The more the rate of combustion reaction increases, the shorter the flame time produced so that the produced flame length decreases. Rhodium (III) Sulphate has more effect in lowering the flame length dimension because it has more magnetic fields in one atom that disrupt the bonding of Castor oil compared to clove oil.

Along with the addition of clove oil and Rhodium (III) Sulphate, the greater the speed of the combustion reaction. This happens because clove oil and Rhodium (III) Sulphate will accelerate the combustion reaction sincr it causes electromagnetic induction which disrupts electrons found in Castor oil and oxygen. In the clove oil molecule, resonance also occurs which creates a magnetic field. This magnetic field is useful to disturb the electrons movement in Castor oil molecules. Electron bonding gets weaker and easier to loose. But in clove oil, the path of electron delocalization is longer because there are additional trajectories on the outer bond. The addition of the delocalization path will also have an impact on the strength or weakness of the magnetic field produced as illustrated in figure 9.

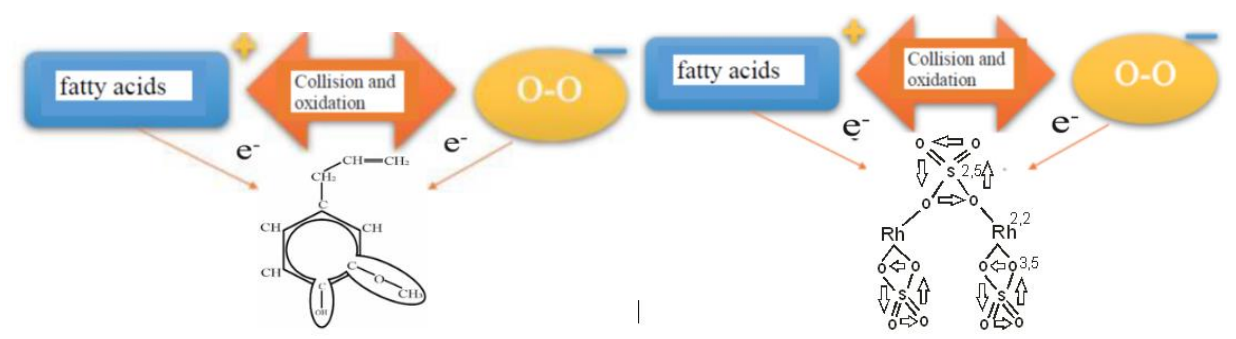

Figure 9. Working illustration of clove oil and Rhodium (III) in influencing Castor oil combustion reactions

In Rhodium (III) Sulfate, the magnetic induced that is caused causes charged fatty acid and oxygen molecules. With the termination of double bonds and single bonds that exist in fatty acids. This causes fatty acids and oxygen to collide. Both catalysts together cause collisions between oxygen molecules and fatty acids. This causes a decrease in 
the activation energy needed for the combustion reaction. So that the combustion reaction that occurs will be faster. Rhodium (III) Sulfate magnetic induction produced is greater than clove oil because it has more magnetic field sources in one atom that disrupt the bonding of Castor oil compared to clove oil.

\section{CONCLUSION}

Addition of catalysts Clove Oil and Rhodium (III) Sulphate affect the combustion characteristics of Castor oil droplets. The catalysts addition was proven to reduce the flame dimension, and ignition delay, but increase the temperature, and accelerate the combustion reaction. Rhodium (III) Sulphate is more effective in influencing the combustion characteristics of Castor oil compared to clove oil catalysts because it has more magnetic field sources in one atom that disrupt the bonding of Castor oil compared to clove oil. The addition of a mixture of clove oil and Rhodium (III) sulfate in Castor oil causes lower combustion characteristics compared to the Rhodium (III) sulfate catalyst. However, the performance of its blend catalyst on the combustion characteristic was still preferable compared to clove oil alone

\section{References}

[1] International Energy Agency. (2012). Renewables energy outlook, World Energy Outlook 2012.

[2] F. Mayasari and R. Dalimi.(2014). Vegetable oil based biodiesel feedstock potential in Indonesia, Makassar International Conference on Electrical Engineering and Informatics, Makasar, Indonesia, pp 37-41

[3] N. Andarwulan, D. Gitapratiwi, A. Laillou, D. Fitriani, P. Hariyadi, R. Moench-Pfanner, and D. Martianto. (2014). Quality of vegetable oil prior to fortification is an important criteria to achieve a health impact, Nutrients, 6, 5051-5060.

[4] Norfazillah Talib, Ramdziah Md. Nasir, Erween Abd. Rahim. (2018). Investigation on the Tribological Behaviour of Modified Jatropha Oil with Hexagonal Boron Nitride Particles as a Metalworking Fluid for Machining Process, International Journal of Integrated Engineering, Vol. 10 No. 3 (2018), 57-62

[5] A. S. Silitonga, A. E. Atabani, T. M. I. Mahlia, H. H. Masjuki, I. A. Badruddin, and S. Mekhilef. (2011). A review on prospect of Jatropha curcas for biodiesel in Indonesia. Renewable and Sustainable Energy Reviews, 15 (2011), 3733-3756.

[6] Ali Ebshish, Zahira Yaakob, Binitha Narayanan, Ahmed Bshish, Wan Ramli Wan Daud. (2011). The Activity of Ni-Based Catalysts on Steam Reforming of Glycerol for Hydrogen Production, International Journal of Integrated Engineering, Vol. 3 No. 1 (2011), 5-8.

[7] N. Nurdjannah and N. Bermawie. (2012). Cloves. Handbook of Herbs and Spices (pp 197-215). Woodhead Publishing Limited.

[8] D. J. Schipper, M. Hutchinson, and K. Fagnou. (2010). Rhodium(III)-catalyzed intermolecular hydroarylation of alkynes. J. Am. Chem. Soc., 130 (20), 6910-1911.

[9] K. Markowitz, M. Moynihan, M. Liu, and S. Kim. (1992). Biologic properties of eugenol and zinc oxideeugenol. A clinically oriented review. Oral Surgery, Oral Med. Oral Pathol, 73(6), 729-737

[10] Amir Khalid, Ridwan Saputra Nursal, Deden Witarsyah Jacob, Norrizam Jaat, Norshuhaila Mohamed Sunar, Shahrin Hisham Amirnordin. (2018). Effect of Ambient Temperature on Ignition Delay, Combustion Process and Emission of Biodiesel Derived from Algae, International Journal of Integrated Engineering, Vol. 10 No. 4 (2018), 43-48. 